\title{
Capital humano y turismo: Rendimiento educativo, desajuste y satisfacción laboral
}

\author{
ADELAIDA LILLO-BAÑULS \\ Departamento de Análisis Económico Aplicado e Instituto Universitario de Investigaciones \\ Turisticas, UNIVERSIDAD DE ALICANTE,ESPAÑA.E-mail: alillo@ua.es \\ JOSÉ MANUEL CASADO-DÍAZ \\ Departamento de Análisis Económico Aplicado e Instituto Universitario de Investigaciones \\ Turísticas, UNIVERSIDAD DE ALICANTE,ESPAÑA.E-mail: jmcasado@ua.es
}

\begin{abstract}
RESUMEN
El capital humano es un elemento clave para el logro de objetivos en términos de competitividad y crecimiento del sector de turismo en España. En este trabajo se utilizan datos muy recientes (procedentes de la Encuesta de Calidad de Vida en el Trabajo, ECVT) para abordar tres aspectos fundamentales en su análisis: el rendimiento educativo que los trabajadores obtienen a cambio de la inversión que realizan en su formación reglada; la medición de los niveles de desajuste entre dicha formación y los puestos de trabajo que ocupan, y su relación con el salario; y, por último, el análisis de diversas dimensiones de la satisfacción laboral y de la relación que se establece entre ellas y la sobreeducación de los trabajadores.
\end{abstract}

Palabras clave: Capital humano, rendimiento educativo, diferencias de género, desajuste educativo, satisfacción y turismo.

\section{Human Capital and Tourism: Returns to Education, Educational Mismatch and Job Satisfaction}

\begin{abstract}
Human capital is a crucial element for the achievement of goals in terms of competitiveness and growth in the Spanish Tourism sector. In this article we use very recent data (from the Quality of Life at Work Survey, ECVT) to tackle three key related aspects: (1) the returns to education obtained by workers in exchange of the investment made in their education/qualifications; (2) the measurement of the existing mismatch between such education/qualifications and their jobs' requirements, and the assessment of its relationship with wages and (3) the analysis of the diverse dimensions of satisfaction with work, and the links between them and workers' education mismatch.
\end{abstract}

Keywords: Human Capital, Returns to Education, Gender Differences, Educational Mismatch, Satisfaction, Tourism.

Clasificación JEL: J24, I21

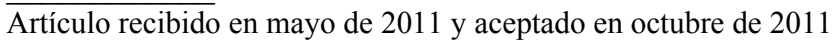

Artículo disponible en versión electrónica en la página www.revista-eea.net, ref. ə-29313 


\section{INTRODUCCIÓN}

El conjunto de actividades económicas que suele englobarse dentro del denominado sector turístico es uno de los más relevantes en España, el país de la OCDE (OCDE, 2010) en el que alcanza un mayor peso relativo tanto en términos de ocupación (13\%) como de valor añadido bruto (11\%). De entre las diversas actividades que constituyen el sector turístico las que ocupan a un mayor número de trabajadores son la hostelería y restauración. En el caso español ambas actividades reúnen a aproximadamente el 65\% de los trabajadores turísticos $(50,1 \%$ en restauración y $14,7 \%$ en actividades relacionadas con el alojamiento). El resto de trabajadores son ocupados en el sector de transporte de viajeros $(12,5 \%)$, las agencias de viajes $(2,5 \%)$ y un conjunto diverso de actividades que suman el 17,9\% de la ocupación en el sector (IET, 2009b).

Precisamente uno de los valores añadidos que se reconocen al turismo, un sector tradicionalmente intensivo en mano de obra, es su capacidad de generación de empleo. En la Tabla 1 se muestra la evolución en los últimos años de la afiliación a la Seguridad Social en actividades de turismo y en el conjunto de la economía. En ella puede observarse claramente cómo 2009 fue el único año en el que el sector turístico perdió afiliados (un 2,2\%) frente a lo ocurrido en el total de la economía, en el que el descenso se inició ya un año antes y, tras una cifra especialmente alta en 2009 (un retroceso del 5,7\%), continuó en 2010; un año este último en el que el sector turístico comenzó a experimentar ya aumentos netos en la afiliación a la Seguridad Social.

\section{Tabla 1}

Trabajadores afiliados al sistema de la Seguridad Social en alta laboral en las actividades características de turismo y en el conjunto de la economía (valor medio de enero a diciembre y variación en relación con el año anterior)

\begin{tabular}{|l|l|l|l|l|}
\hline Año & \multicolumn{2}{|c|}{ Turismo } & \multicolumn{2}{c|}{ Total } \\
\hline 2006 & $1.846,5$ & $5,0 \%$ & $18.596,3$ & $4,3 \%$ \\
\hline 2007 & $1.937,2$ & $4,9 \%$ & $19.152,3$ & $3,0 \%$ \\
\hline 2008 & $1.959,6$ & $1,2 \%$ & $19.005,6$ & $-0,8 \%$ \\
\hline 2009 & $1.917,4$ & $-2.2 \%$ & $17.916,8$ & $-5,7 \%$ \\
\hline 2010 & $1.932,2$ & $0.8 \%$ & $17.581,9$ & $-1,9 \%$ \\
\hline
\end{tabular}

Fuente: IET (2009b) y Ministerio de Trabajo e Inmigración.

El mercado laboral turístico se ha caracterizado tradicionalmente por la inestabilidad de gran parte de los puestos de trabajo, por una elevada rotación, menores retribuciones que en otros sectores, elevadas jornadas y tiempos de 
trabajo diferentes a los existentes en otros sectores de actividad económica. Especialmente en el subsector de hostelería y restauración, la rama turística más representativa en el sector, se observa una mayor presencia de mujeres, jóvenes e inmigrantes y un porcentaje significativo de trabajadores con niveles educativos bajos o primarios. Algunas cifras recientes pueden ilustrar algunos de estos aspectos en el caso español. Destaca, por ejemplo, la alta proporción de asalariados con contrato temporal $(31,4 \%$ en 2009$)$, que supera el promedio nacional para ese mismo año $(25,4 \%)$, siendo especialmente importante la incidencia de este tipo de contratos en el caso de las mujeres. En cuanto a la jornada laboral, los asalariados a tiempo parcial representaron un $20,5 \%$ del total. Por otro lado, la población extranjera ocupada en el sector de turismo suponía el $22,9 \%$ del total de la ocupación en 2009 , superando así su presencia en comparación con el total del sector servicios $(13,4 \%)$ y el promedio nacional $(13,9 \%)$. De ella, la mayor parte, un $86 \%$, estaba ocupada en la rama de hostelería. En cuanto a las mujeres, un $73,8 \%$ de las mujeres asalariadas en turismo que trabajaron con contrato indefinido y el $77,8 \%$ de las que lo hicieron con contrato temporal estaban ocupadas en actividades de hostelería y restauración (IET, 2009b). Algunos de los resultados del Libro Blanco de los Recursos Humanos en Turismo (Exceltur, 2004) abundan en una caracterización relativamente negativa del empleo en el sector: horarios de trabajo incómodos (incluyendo vacaciones, fines de semana, y turnos vespertinos y nocturnos); un número de horas de trabajo semanal superiores a los de otros sectores, salarios poco competitivos, trabajos que requieren poca o ninguna cualificación, baja inversión en formación, pocas perspectivas de desarrollo de carrera, escasos reconocimiento externo y prestigio social, entre otros aspectos.

Nos encontramos, por tanto, con un sector muy relevante en nuestro país, que cuenta con indudables ventajas comparativas en él; un sector con una gran capacidad de generación de empleo incluso en momentos adversos del ciclo económico reciente, y que suele nutrirse de algunos de los colectivos más desfavorecidos en el mercado laboral (mujeres, jóvenes, inmigrantes). Se trata, por otro lado, y de manera no independiente de lo anterior, de un conjunto de actividades con bajos niveles de productividad y que se enfrenta a los mismos retos que el resto de sectores económicos en un contexto de competencia internacional cada vez mayor, que hace necesaria la adopción de medidas que permitan mejorar su competitividad. Parece indudable que gran parte de la capacidad para abordar estos retos vendrá de la mano de mejoras en su capital humano, del que suele señalarse que forma parte del servicio que se ofrece (Acosta et al., 2002; Lillo, 2009b). Es en este último aspecto en el que se centra este trabajo, que se ocupa de tres aspectos fundamentales e interrelacionados del capital humano turístico en España a partir de los datos más recientes: (a) el rendimiento que los trabajadores obtienen a cambio de la inversión que realizan en su formación reglada; (b) la medición de los niveles de desajuste entre dicha 
formación y la requerida por los puestos de trabajo ocupados, y la relación entre la existencia de dichos desajustes y los rendimientos estimados y (c) el análisis de las diversas dimensiones de la satisfacción con el puesto de trabajo desempeñado, y su relación con el nivel de desajuste existente entre la formación del trabajador y el puesto de trabajo que éste ocupa.

Para ello este trabajo comienza, en el siguiente apartado, con un breve análisis de los niveles de formación de los asalariados que trabajan en actividades características del sector turístico en el periodo 2006-2009, a partir de los datos que proporciona la Encuesta de Calidad de Vida en el Trabajo (ECVT) que realiza anualmente el Ministerio de Trabajo e Inmigración. Se analiza a continuación la recompensa que a través de sus remuneraciones reciben los trabajadores del sector, lo que denominamos rendimiento privados de la educación. Se exploran, en este sentido, las diferencias entre hombres y mujeres tanto en su educación como en el rendimiento que de la misma obtienen en su desempeño laboral. Los resultados ponen de manifiesto la existencia de diferencias significativas en el subsector de hostelería y restauración. En el tercer epígrafe se realiza un análisis de la posible existencia de sobreeducación en el sector y su efecto sobre el rendimiento educativo en trabajadores de turismo y, en el apartado siguiente, se exploran diversos parámetros de medición de la satisfacción laboral en el sector y su relación con la existencia de sobreeducación. Por último, se presentan las principales conclusiones obtenidas.

\section{EL RENDIMIENTO EDUCATIVO EN EL SECTOR TURÍSTICO}

El término capital humano designa los conocimientos, competencias y habilidades útiles para la producción de bienes, servicios y nuevos conocimientos que son acumulados por los individuos en el proceso de educación y formación así como a lo largo de su experiencia laboral. Dicho término engloba, además, la capacidad y el talento innatos, y suele estar fuertemente condicionado por el entorno del individuo, especialmente el familiar. Una de las formas más habituales de cuantificar el capital humano es la medición de la variable educación, ya sea a través de los máximos niveles educativos alcanzados por los individuos o mediante la consideración de los años que éstos han dedicado a su formación reglada.

La Tabla 2 confirma un hecho bien constatado en la literatura sobre el capital humano en el sector turístico: sus bajos niveles formativos en comparación con otras actividades económicas ${ }^{1}$. Así, aproximadamente el 50\% de los asalariados

\footnotetext{
${ }^{1}$ Siguiendo el criterio seguido por el Instituto de Estudios Turísticos, obtenemos a través de los códigos de la Clasificación Nacional de Actividades Económicas (CNAE) la submuestra de aquellos ocupados que desarrollan su trabajo en las actividades características del turismo (hos-
} 
del sector se concentran en los dos niveles de estudios más bajos, primarios y secundarios, lo que supone diez puntos porcentuales más que lo observado para el conjunto de la economía. En el otro extremo de la escala educativa, los titulados universitarios tienen un peso que es prácticamente la mitad que el existente para el total de actividades económicas $(26,6 \%)^{2}$. Esta situación es mucho más acentuada cuando se considera el subsector de hostelería y restauración, entre cuyos ocupados los universitarios suponen menos del $10 \%$ del total y quienes únicamente tienen estudios primarios y secundarios representan casi el 57\%. El panorama que dibujan estos resultados es, lógicamente, negativo, en términos de competitividad. Una mano de obra menos formada es en principio menos proclive a la generación y/o adopción de innovaciones de todo tipo (tecnológicas, organizativas, entre otras), tiene una menor capacidad de adaptación a los cambios y menos posibilidades, por tanto, de contribuir a mejorar la competitividad del sector. Desde otro punto de vista, el bajo nivel educativo de los ocupados en el sector turístico podría no ser más que la otra cara de la moneda de un sector en el que abundan los puestos de trabajo con muy escasos requerimientos formativos, especialmente en las actividades de hostelería y restauración, o bien ser reflejo de una incapacidad para atraer trabajadores cualificados debido a razones pecuniarias y/o a otras características de los puestos de trabajo tales como las reseñadas anteriormente.

Tabla 2

Trabajadores por nivel de estudios

\begin{tabular}{|c|c|c|c|}
\hline $\begin{array}{c}\text { Nivel de } \\
\text { educación: }\end{array}$ & Total & Turismo & $\begin{array}{c}\text { Hostelería y } \\
\text { restauración }\end{array}$ \\
\hline Primarios $\left(\mathrm{E}_{1}\right)$ & $19,76 \%$ & $23,64 \%$ & $27,36 \%$ \\
\hline Secundarios $\left(\mathrm{E}_{2}\right)$ & $20,67 \%$ & $27,61 \%$ & $29,41 \%$ \\
\hline F. Profesional $\left(\mathrm{E}_{3}\right)$ & $19,62 \%$ & $18,32 \%$ & $15,80 \%$ \\
\hline Bachillerato $\left(\mathrm{E}_{4}\right)$ & $13,37 \%$ & $16,75 \%$ & $17,78 \%$ \\
\hline Universitarios $\left(\mathrm{E}_{5}\right)$ & $26.58 \%$ & $13,69 \%$ & $9,64 \%$ \\
\hline
\end{tabular}

Nota: Primarios (5 cursos de EGB o equivalentes, Certificado de escolaridad); Secundarios (Primer ciclo de la ESO, Graduado escolar, EGB o equivalentes).

Fuente: Elaboración propia a partir de la Encuesta de Calidad de Vida en el Trabajo 2006-2009 (Ministerio de Trabajo e Inmigración).

telería y restauración, transportes, agencias de viajes, operadores turísticos y actividades recreativas, culturales y deportivas).

${ }^{2}$ Se trata, sin embargo, de unos datos que mejoran ligeramente los observados por Lillo (2009) a partir de la misma fuente estadística para el período 1999-2002, cuando los ocupados con estudios primarios y secundarios suponían el 57\% del total del sector turístico y los universitarios un $11 \%$. 
Uno de los marcos teóricos más utilizados para analizar los aspectos salariales del capital humano es el propuesto por Becker (1964), y se basa en la idea de que la inversión en educación incrementa la productividad de los trabajadores, lo que hace lógico que los niveles retributivos de quienes dedican más años a sus estudios sean mayores. El cálculo de la tasa de rendimiento educativo trata de medir sobre la base de esta teoría la relación existente entre los ingresos de los individuos y el nivel de estudios alcanzado. Se trata de una rama de la literatura que ha recibido numerosísimas contribuciones empíricas en las últimas décadas. En el caso español pueden señalarse, entre otros, los trabajos de Alba y Sansegundo, Arrazola y Hevia (2003 y 2008); Arrazola et al. (2000, 2001 y 2003); Marcenaro y Navarro (2005), Pastor et al. (2007), Raymond et al. (2009), Lillo y Casado (2010b). En lo que respecta al turismo los análisis de este tipo son mucho menos abundantes, aunque han proliferado en los últimos años: Lillo y Ramón (2005), Santos y Varejão (2007), Thrane (2008 y 2010), Lillo (2009), Lillo y Casado (2010a), Campos et al., (2009 y 2011), entre otros.

\subsection{Metodología y datos}

Para el cálculo del rendimiento privado de la educación seguimos, como es habitual en este tipo de análisis, la propuesta de especificación de ecuaciones salariales de Mincer (1974), cuya forma funcional viene dada por la ecuación [1]. En su formulación tradicional esta ecuación minceriana permite estimar, como puede observarse, el efecto de la educación y la experiencia de los individuos sobre sus ingresos salariales:

$$
\log W_{i}=\beta_{o}+\beta_{1} E_{i}+\beta_{2} X_{i}+\beta_{3} X^{2}{ }_{i}+u_{i}
$$

La variable dependiente, el salario hora ${ }^{3} W_{i}$ adopta la forma logarítmica, de manera que los coeficientes estimados pueden ser interpretados en términos de tasas de rendimientos. Los regresores incluidos hacen referencia a los años de estudio $^{4}, E_{i}$ y la experiencia laboral ${ }^{5}$ de los trabajadores, $X_{i}$ (que se incluye

${ }^{3}$ La ECVT ofrece información sobre los ingresos mensuales netos procedentes del trabajo agrupados en un número elevado de intervalos, nueve, cuyas marcas de clase han sido utilizadas como estimador de la renta laboral percibida (una práctica frecuente al usar esta fuente estadística: Gamero, 2007, 2009 y 2010), que luego ha sido transformada en salario hora a partir de la información sobre el tiempo semanal de trabajo.

${ }^{4}$ La fuente estadística ofrece información sobre el nivel de estudios más alto alcanzado por el individuo, a partir del cual se ha imputado el número de años necesario para completarlo, siguiendo la práctica habitual en la literatura española e internacional.

${ }^{5}$ Con mucha frecuencia esta variable se aproxima mediante el cálculo de la diferencia entre la edad del individuo y una edad ficticia de inicio de la vida laboral estimada imputando el número de años mínimo necesario para cursar los estudios reglados de mayor nivel que el individuo declara poseer. La ECVT permite, sin embargo, una estimación mucho más ajustada, de tal 
también al cuadrado). Siguiendo una estrategia frecuente no se incorporan más variables explicativas en el modelo pues el objeto de este trabajo es capturar la tasa de rendimiento educativo en el sector sin que se vea mermada por la inclusión de más variables. La tasa privada de rentabilidad de la educación es el coeficiente $\beta_{1}$ de la variable educación, que en la ecuación [1] aparece como variable continua, el número de años de estudios ${ }^{6}$, lo que implica asumir que el rendimiento marginal de la educación es constante. Este supuesto se relaja en la ecuación [2], en la que la educación se incluye como una variable discreta y los coeficientes $\beta_{1}-\beta_{4}$ pueden ser usados para estimar las diferencias salariales que, en relación con la categoría de referencia ( $E_{1}$, estudios primarios), obtienen los individuos que han completado estudios secundarios $\left(E_{2}\right)$, formación profesional $\left(E_{3}\right)$, bachillerato $\left(E_{4}\right)$ o universitarios $\left(E_{5}\right)$.

$$
\log W_{i}=\beta_{o}+\beta_{1} E_{2}+\beta_{2} E_{3}+\beta_{3} E_{4}+\beta_{4} E_{5}+\beta_{5} X_{i}+\beta_{6} X^{2}{ }_{i}+u_{i}
$$

Los datos utilizados se refieren a asalariados de edades comprendidas entre los 16 y 64 años y provienen de la Encuesta de Calidad de Vida en el Trabajo (ECVT), a partir de la cual se ha construido un pool para el periodo 2006$2009^{7}$. Esta encuesta contiene información de trabajadores que desarrollan su actividad laboral en empresas de cualquier tamaño, incluso las de un único trabajador, lo que es particularmente importante a la hora de analizar un sector como el de turismo, caracterizado por la existencia de muchas pequeñas empresas. Además, esta fuente estadística permite aproximar con mucha exactitud la experiencia real del trabajador y contiene variables que hacen posible el análisis de otros aspectos importantes para el objeto de este trabajo, tales como el desajuste educativo o la satisfacción de los ocupados con distintos aspectos de sus condiciones laborales. Cabe señalar, por último, que dado que los datos utilizados son de corte transversal las estimaciones se realizan considerando errores robustos en heterocedasticidad.

\footnotetext{
forma que para individuos que declaran estar realizando su primer trabajo la experiencia se calcula como la diferencia entre el año en curso y el de inicio de dicho trabajo, y para el resto de individuos se calcula como la diferencia entre el año en curso y aquél en el que empezaron a trabajar por primera vez un mínimo de tres meses seguidos.

${ }^{6}$ Este coeficiente sería la elasticidad de los ingresos-educación, es decir el valor esperado de la derivada parcial del logaritmo de ingresos respecto a la educación recibida. Es decir, $\beta_{1}$ representaría el aumento en la retribución de cada año adicional de educación que, en ausencia de costes directos, es equiparable a la TIR, tasa interna de retorno.

${ }^{7}$ Se sigue así una estrategia ya usada en otros trabajos realizados a partir de esta misma fuente de datos: Lillo y Ramón (2005); Lillo y Casado (2010a y 2010b); Gamero (2010), entre otros. El pool de datos permite obtener una muestra de total de 20.829 individuos, 2.388 individuos para la submuestra de trabajadores en actividades características del sector de turismo y 1.173 para la submuestra de hostelería y restauración.
} 


\subsection{Estimaciones y resultados}

La Tabla 3 recoge los resultados obtenidos al estimar la ecuación 2 mediante MCO (los resultados de la ecuación 1 se presentan en la Tabla 7 junto con los de la ecuación 3 ).

Tabla 3

Ecuaciones de ingresos

\begin{tabular}{|c|c|c|c|c|c|c|c|}
\hline \multirow[t]{2}{*}{ Ln ingresos hora } & \multirow[t]{2}{*}{ Total } & \multicolumn{3}{|c|}{ Turismo } & \multicolumn{3}{|c|}{ Hostelería y Restauración } \\
\hline & & Total & Mujeres & Hombres & Total & Mujeres & Hombres \\
\hline E2 & $\begin{array}{l}0.064^{*} \\
(0.007) \\
\end{array}$ & $\begin{array}{l}0.071^{*} \\
(0.022) \\
\end{array}$ & $\begin{array}{c}0.063 \\
(0.039) \\
\end{array}$ & $\begin{array}{l}0.071^{*} \\
(0.027) \\
\end{array}$ & $\begin{array}{l}0.069^{* *} \\
(0.028) \\
\end{array}$ & $\begin{array}{l}0.081^{\text {** }} \\
(0.037) \\
\end{array}$ & $\begin{array}{c}0.051 \\
(0.041) \\
\end{array}$ \\
\hline E3 & $\begin{array}{l}0.177^{*} \\
(0.008) \\
\end{array}$ & $\begin{array}{l}0.174^{*} \\
(0.026) \\
\end{array}$ & $\begin{array}{l}0.154^{*} \\
(0.045) \\
\end{array}$ & $\begin{array}{l}0.177^{*} \\
(0.031) \\
\end{array}$ & $\begin{array}{l}0.114^{*} \\
(0.034) \\
\end{array}$ & $\begin{array}{l}0.115^{\star *} \\
(0.045) \\
\end{array}$ & $\begin{array}{l}0.107^{* *} \\
(0.052) \\
\end{array}$ \\
\hline E4 & $\begin{array}{l}0.207^{*} \\
(0.009) \\
\end{array}$ & $\begin{array}{c}0.151^{*} \\
(0.0026) \\
\end{array}$ & $\begin{array}{l}0.167^{*} \\
(0.041) \\
\end{array}$ & $\begin{array}{l}0.146^{*} \\
(0.034) \\
\end{array}$ & $\begin{array}{l}0.151^{*} \\
(0.032) \\
\end{array}$ & $\begin{array}{l}0.135^{\star} \\
(0.039) \\
\end{array}$ & $\begin{array}{l}0.173^{*} \\
(0.051) \\
\end{array}$ \\
\hline E5 & $\begin{array}{l}0.523^{*} \\
(0.008) \\
\end{array}$ & $\begin{array}{l}0.324^{*} \\
(0.031) \\
\end{array}$ & $\begin{array}{l}0.307^{*} \\
(0.045) \\
\end{array}$ & $\begin{array}{l}0.356^{*} \\
(0.044) \\
\end{array}$ & $\begin{array}{l}0.253^{*} \\
(0.039) \\
\end{array}$ & $\begin{array}{l}0.234^{*} \\
(0.054) \\
\end{array}$ & $\begin{array}{l}0.271^{*} \\
(0.070) \\
\end{array}$ \\
\hline Experiencia & $\begin{array}{l}0.017^{*} \\
(0.000) \\
\end{array}$ & $\begin{array}{l}0.013^{*} \\
(0.002) \\
\end{array}$ & $\begin{array}{l}0.010^{*} \\
(0.003) \\
\end{array}$ & $\begin{array}{l}0.013^{*} \\
(0.003) \\
\end{array}$ & $\begin{array}{l}0.007^{*} \\
(0.002) \\
\end{array}$ & $\begin{array}{l}0.011^{*} \\
(0.003)\end{array}$ & $\begin{array}{c}0.005 \\
(0.004) \\
\end{array}$ \\
\hline Experiencia $^{2}$ & $\begin{array}{l}-0.000^{*} \\
(0.000)\end{array}$ & $\begin{array}{l}-0.000^{*} \\
(0.000)\end{array}$ & $\begin{array}{c}-0.000^{* * *} \\
(0.000)\end{array}$ & $\begin{array}{l}-0.000^{*} \\
(0.000) \\
\end{array}$ & $\begin{array}{l}-0.000 \\
(0.000) \\
\end{array}$ & $\begin{array}{c}-0.000^{* *} \\
(0.000)\end{array}$ & $\begin{array}{l}-0.000 \\
(0.000) \\
\end{array}$ \\
\hline Constante & $\begin{array}{l}1.544^{*} \\
(0.030) \\
\end{array}$ & $\begin{array}{l}1.617^{*} \\
(0.027) \\
\end{array}$ & $\begin{array}{l}1.587^{*} \\
(0.045) \\
\end{array}$ & $\begin{array}{l}1.653^{*} \\
(0.034) \\
\end{array}$ & $\begin{array}{l}1.603^{*} \\
(0.031) \\
\end{array}$ & $\begin{array}{c}1.548^{*} \\
(0.041) \\
\end{array}$ & $\begin{array}{l}1.673^{*} \\
(0.050) \\
\end{array}$ \\
\hline $\mathrm{R}^{2}$ & 0.24 & 0.07 & 0.074 & 0.084 & 0.05 & 0.05 & 0.05 \\
\hline $\mathrm{n}$ & 20829 & 2388 & 971 & 1417 & 1173 & 661 & 512 \\
\hline
\end{tabular}

*Significativo al 1\%; **Significativo al 5\%; ***Significativo al $10 \%$.

Errores estándard robustos entre paréntesis.

Categoría de referencia: E1.

Fuente: Elaboración propia a partir de los datos de la ECVT (2006-2009).

Tabla 4

Diferencias entre niveles educativos

\begin{tabular}{|l|r|r|r|r|r|r|r|}
\hline & Muestra total & \multicolumn{3}{|c|}{ Turismo } & \multicolumn{3}{c|}{ Hostelería y restauración } \\
\hline & & Total & Mujeres & Hombres & Total & Mujeres & Hombres \\
\hline $\mathrm{E}_{2} / \mathrm{E}_{1}$ & $6,67 \%$ & $7,44 \%$ & $6.58 \%$ & $7,40 \%$ & $7,19 \%$ & $8,54 \%$ & $5,28 \%$ \\
\hline $\mathrm{E}_{3} / \mathrm{E}_{1}$ & $19,48 \%$ & $19,03 \%$ & $16.70 \%$ & $19.48 \%$ & $12,13 \%$ & $12,25 \%$ & $11,32 \%$ \\
\hline $\mathrm{E}_{4} / \mathrm{E}_{1}$ & $23,06 \%$ & $16,32 \%$ & $18.24 \%$ & $15.72 \%$ & $16,38 \%$ & $14,45 \%$ & $18,88 \%$ \\
\hline $\mathrm{E}_{5} / \mathrm{E}_{1}$ & $68,79 \%$ & $38,32 \%$ & $35.97 \%$ & $42.89 \%$ & $28,83 \%$ & $26,46 \%$ & $31,22 \%$ \\
\hline
\end{tabular}

Fuente: Elaboración propia a partir de los datos de la Tabla 3. 
Los resultados obtenidos permiten extraer varias conclusiones. En primer lugar, e independientemente del grupo de actividades considerado, un mayor nivel de estudios se relaciona con salarios más altos, en línea con lo predicho por la teoría. Esta circunstancia es especialmente clara en la Tabla 4, en la que se calcula la remuneración adicional obtenida por quienes han alcanzado cada uno de los niveles educativos en relación con la categoría de referencia, la de estudios primarios $\left(E_{l}\right)$ que, recuérdese (Tabla 2), agrupa al 23,64\% de los ocupados en el sector turístico y al $27,36 \%$ en el caso del subsector de hostelería y restauración. Las diferencias son especialmente notorias en el caso de los titulados universitarios, cuyas retribuciones son un $68,79 \%$ superiores a las de quienes únicamente tienen estudios primarios; una cifra que se reduce más de treinta puntos porcentuales entre los ocupados en el sector turístico (hasta el $38,32 \%)$ y, muy notablemente, en el caso de quienes se ocupan en la hostelería y restauración, donde la remuneración de los universitarios sólo supera la de quienes tienen estudios primarios en un $28,83 \%{ }^{8}$. Los rendimientos son mayores en la muestra total que en la que considera los ocupados en las distintas actividades turísticas salvo en el caso de los estudios secundarios, que parecen haberse convertido en un mínimo imprescindible para el desempeño de la actividad laboral en el sector. La menor magnitud de los rendimientos de la educación en las actividades turísticas se confirma cuando se estima la ecuación $1 \mathrm{y}$, por lo tanto, la educación es tratada como una variable continua (Tabla 7), dado que también en ese caso el rendimiento educativo es inferior para los trabajadores de turismo $(2,7 \%)$ y hostelería y restauración $(2,1 \%)$ que para el conjunto de la muestra $(4,8 \%)$. Se trata de un resultado obtenido ya en investigaciones realizadas para el periodo 1999-2003 a partir de la misma fuente $(\text { Lillo, 2009a })^{9}$ cuya comparación permite atisbar una tendencia de reducción generalizada en el rendimiento educativo a lo largo del último decenio.

Un resultado relevante observable en la Tabla 4 es que en el sector turístico, y a diferencia de lo que ocurre cuando se considera la economía en su conjunto (y también en el subsector de hostelería y restauración), la formación profesional se valora más que el bachillerato, lo que se debe a que entre los hombres el premio de los estudios de formación profesional en relación con los estudios primarios es de un 19,48\% frente al $15,72 \%$ que suponen los estudios de bachillerato.

En lo que respecta a la experiencia, la Tabla 3 muestra que ésta se remunera en mucha mayor medida en la economía en su conjunto que en el sector turís-

\footnotetext{
${ }^{8}$ Todo ello en un contexto en el que, según las muestras utilizadas, procedentes de la ECVT 2006-2009, el salario hora es notablemente inferior en el sector turístico $(6,95 ; 6,18$ en el subsector de hostelería y restauración) que en la economía considerada en su conjunto $(7,70)$.

${ }^{9}$ Para el periodo $1999-2003$, los rendimientos educativos son del 5,6\%; 3,6\% y 2,3\% para el total, turismo y hostelería respectivamente.
} 
tico y, muy especialmente, la hostelería y restauración donde, de hecho, no resulta significativa entre los trabajadores varones. Esta circunstancia, que se confirma cuando se considera la educación como variable continua (Tabla 7), podría estar relacionada con alguna de las características menos atractivas del empleo en el sector; a saber, la elevada temporalidad y rotación en los puestos de trabajo, y los bajos requisitos formativos comúnmente asociados a ellos. Por último, y en lo que se refiere a las diferencias entre ocupados varones y mujeres, la recompensa alcanzada en relación con la categoría de referencia es notoria en el caso de los ocupados con estudios universitarios (por ejemplo, en el caso del turismo supone un $42,89 \%$ para los hombres y un $35,97 \%$ para las mujeres).

La conclusión más relevante de este apartado es, sin lugar a dudas, que los rendimientos que los ocupados obtienen a cambio de su inversión en formación reglada es mucho menor en el caso de las actividades turísticas que en la economía considerada en su conjunto, y que la diferencia es especialmente notable en el subsector de hostelería y restauración. De entre las implicaciones de resultado cabe destacar en primer lugar, desde un punto de vista global, que los incentivos para la formación son probablemente menores en este sector que en otros, lo que podría contribuir a alejar del mismo a quienes tienen mayores niveles de cualificación, generando así problemas de competitividad en el medio y largo plazo (un sector de puestos de trabajo poco atractivos que no consigue reclutar personal con mayores cualificaciones lo que, a su vez, dificulta la innovación y las mejoras en productividad y retroalimenta la poca calidad de los puestos de trabajo que se ofrecen). Por otro lado, desde un punto de vista territorial debe considerarse que, tal y como se ha señalado, la actividad turística no es igualmente relevante en todos los mercados de trabajo regionales y locales. En la medida en que algunos de dichos mercados sean fuertemente dependientes de este sector se puede estar generando una percepción poco favorecedora hacia la educación (¿por qué estudiar si la recompensa es tan baja en relación con otras inversiones alternativas?). Si ello ocurriera los efectos sobre la competitividad a medio y largo plazo no se limitarían al propio sector, sino que podrían alcanzar a la economía regional/local en su conjunto, en la medida en que las expectativas de empleo estarán, lógicamente, ligadas a los sectores preponderantes.

\section{DESAJUSTE EDUCATIVO: SOBREDUCACIÓN EN TURISMO}

\subsection{Una aproximación al desajuste educativo}

Dadas las características que la mayor parte de los organismos internacionales atribuyen al empleo en el sector turístico, una parte de la explicación de los menores rendimientos de la educación en el sector turístico podría estar relacionada con un problema de desajuste educativo. Éste podría producirse si, por ejemplo, los ocupados (o parte de ellos) tuvieran una formación demasiado 
elevada para el desempeño de sus tareas laborales dados los requisitos de los puestos que ocupan, lo que se conoce como sobreeducación, un fenómeno que en el caso del mercado de trabajo turístico español ha sido analizado por Marchante et al. (2003 y 2005).

De entre los métodos usados para medir la sobreeducación destacan los siguientes (Blanco, 1997): El método objetivo parte de la elaboración de una clasificación de puestos en la que se determina el nivel educativo que se considera necesario para su desempeño, que es comparado con el del individuo analizado. Los métodos subjetivos se basan, por su parte, en los datos obtenidos de encuestas a trabajadores, que responden a preguntas relativas a sus características personales y a las del puesto de trabajo que ocupan. Dentro de este grupo se distingue entre el método subjetivo indirecto, en el que se compara el nivel educativo alcanzado por el trabajador con el nivel que éste señala como óptimo para ocupar el puesto de trabajo que desarrolla, y el método subjetivo directo, que clasifica al trabajador como sobreeducado o no dependiendo de la opinión de éste sobre el ajuste entre su formación y la requerida por el puesto que ocupa. Por último, según el llamado método estadístico se considera sobrecualificado a aquel trabajador cuyos años de educación formal superan en una desviación típica los años medios de educación de los trabajadores que pertenecen a su mismo grupo ocupacional. La selección del método concreto para la medida de la sobreeducación suele estar guiada por la información disponible en la base de datos utilizada (Murillo et al, 2010).

En Blanco (1997) se discuten pormenorizadamente las ventajas e inconvenientes de cada uno de los métodos. Así, por ejemplo, el método objetivo es complejo de aplicar ya que la tarea de clasificar los puestos de trabajo requiere gran cantidad de información y, por otro lado, la clasificación desarrollada no puede recoger las particularidades de cada puesto de trabajo específico, para cada uno de los cuales el mejor conocedor es probablemente el trabajador que los desempeña, pese a la subjetividad inherente a su apreciación. El método estadístico, por su parte, necesita de poca información pero para Blanco (1997:283) su fiabilidad es menor debido a que "en primer lugar se acepta implícitamente que el número de años de educación adecuada se encuentra aproximadamente en la media. En segundo lugar, la frontera de una desviación típica es bastante arbitraria".

A partir de la información disponible en la ECVT, la Tabla 5 presenta una primera aproximación a la medición del desajuste educativo utilizando el método subjetivo directo ${ }^{10}$. Los datos muestran que la sobreeducación afecta a

${ }^{10}$ De acuerdo con lo señalado el trabajador se clasifica como sobreeducado o no dependiendo de su respuesta a la pregunta que se le formula en la encuesta en cuanto a si considera que su nivel de estudios es suficiente para desempeñar su trabajo actual. Dicha respuesta tiene como alternativas las cuatro categorías incluidas en la Tabla 5. 
alrededor de un $19 \%$ de los ocupados; una cifra que se eleva al $21,18 \%$ en el sector turístico y alcanza a casi el $25 \%$ de los empleados en el subsector de la hostelería y la restauración ${ }^{11}$. Frente a estas cifras se constata la práctica irrelevancia de la infraeducación, que se da entre aproximadamente el 3\% de los ocupados (aunque de nuevo en una mayor proporción en el subsector de hostelería y restauración).

Tabla 5

Desajuste educativo (\%)

\begin{tabular}{|l|c|c|c|}
\hline & Total & Turismo & $\begin{array}{c}\text { Hostelería y } \\
\text { restauración }\end{array}$ \\
\hline Adecuadamente educado & 76,68 & 73,93 & 69,84 \\
\hline Sobreducación & 18,98 & 21,18 & 24,62 \\
\hline Infraeducación & 2,11 & 2,06 & 2,33 \\
\hline Necesita una formación distinta & 2,23 & 2,83 & 3,21 \\
\hline
\end{tabular}

Fuente: Elaboración propia a partir de la Encuesta de Calidad de Vida en el Trabajo 2006-2009 (Ministerio de Trabajo e Inmigración).

La Tabla 6 pone de manifiesto que, tal y como cabía esperar, la sobreeducación no se distribuye homogéneamente entre los distintos niveles educativos, sino que es mucho más frecuente cuanto mayores son éstos, de tal forma que llega a afectar a casi la mitad de los ocupados del sector turístico que cuentan con estudios universitarios; una cifra que alcanza a aproximadamente el $60 \%$ de los universitarios empleados en el subsector de hostelería y restauración.

Tabla 6

Porcentaje de desajuste educativo en turismo y hostelería y restauración por nivel de estudios

\begin{tabular}{|l|c|c|c|c|c|c|}
\hline & \multicolumn{3}{|c|}{ Turismo } & \multicolumn{3}{c|}{ Hostelería y restauración } \\
\hline Nivel de educación: & Adecuado & Sobre & Infra & Adecuado & Sobre & Infra \\
\hline Primarios & $86 \%$ & $7 \%$ & $3 \%$ & $85 \%$ & $8 \%$ & $3 \%$ \\
\hline Secundarios & $83 \%$ & $12 \%$ & $2 \%$ & $77 \%$ & $17 \%$ & $2 \%$ \\
\hline
\end{tabular}

${ }^{11}$ Se trata de cifras similares a las obtenidas en Lillo (2009b) a partir de un pooling distinto de datos procedentes de la misma fuente referidos al periodo comprendido entre 1999 y 2002, en el que estimaba que la sobreeducación afectaba a un 19\% de los empleados en los servicios turísticos. Concuerdan también con las de Marchante et al. (2003), quien obtiene para su muestra de trabajadores de hostelería (procedente de una encuesta propia realizada en Andalucía) un $17,5 \%$ de sobreeducados; una cifra que se eleva hasta el $61,5 \%$ cuando los titulados universitarios ocupados en el sector son considerados por separado. 
Tabla 6 (continuación)

Porcentaje de desajuste educativo en turismo y hostelería y restauración por nivel de estudios

\begin{tabular}{|l|c|c|c|c|c|c|}
\hline & \multicolumn{3}{|c|}{ Turismo } & \multicolumn{3}{c|}{ Hostelería y restauración } \\
\hline Nivel de educación: & Adecuado & Sobre & Infra & Adecuado & Sobre & Infra \\
\hline F. Profesional & $69 \%$ & $24 \%$ & $2 \%$ & $62 \%$ & $30 \%$ & $2 \%$ \\
\hline Bachillerato & $65 \%$ & $31 \%$ & $2 \%$ & $59 \%$ & $37 \%$ & $2 \%$ \\
\hline Universitarios & $50 \%$ & $46 \%$ & $0.7 \%$ & $34 \%$ & $60 \%$ & $1 \%$ \\
\hline
\end{tabular}

Nota: La diferencia hasta 100\% son aquellos trabajadores que dicen necesitar una formación distinta.

Fuente: Elaboración propia a partir de la Encuesta de Calidad de Vida en el Trabajo 2006-2009 (Ministerio de Trabajo e Inmigración).

La sobrecualificación está relacionada, lógicamente, con un exceso de oferta de trabajadores cualificados en relación con la demanda de sus servicios por parte de las empresas del sector ${ }^{12}$. Dado que la presencia de universitarios entre los ocupados en el sector turístico es menor que en otros ámbitos, parece claro que la mayor sobreeducación observada está en mayor medida relacionada con el segundo de los términos, la incapacidad del sector para ofrecer puestos de trabajo con un mayor nivel de requerimientos en términos de cualificación. Ello podría empujar a ciertos individuos con un mayor nivel educativo a aceptar trabajos de menores requerimientos educativos que los que efectivamente poseen y provocar diversos efectos adversos. Desde el punto de vista social parece claro que la sobrecualificación es una manifestación de un fallo en la asignación de los recursos productivos, cuyo uso queda al menos en parte ocioso en lo que se refiere al capital humano de los individuos afectados por ella. Este fenómeno podría, además, suponer un perjuicio para los trabajadores de menor nivel educativo, que en ocasiones se verían desplazados por los de mayor nivel lo que, a su vez, les podría llevar a aceptar trabajos con unas exigencias formativas inferiores a las suyas, contagiando así este fenómeno a otros niveles. A ello se añaden los efectos de la sobrecualificación en cuanto a la motivación de los individuos y su bienestar, lo que podría redundar de manera negativa sobre la productividad, dándose así la paradoja de que los trabajadores más preparados pudieran resultar a la postre menos productivos si las características de los puestos que ocupan no fueran acordes a su formación. En sentido contrario, podría ocurrir que los efectos de la sobreeducación no sean totalmente negativos. Al-

${ }^{12}$ Se trata de un fenómeno que en el caso del turismo podría verse acentuado, además, por el notable aumento de quienes siguen estos estudios en las universidades españolas. Así, entre el curso 1988/89 y 2008/2009 el número de matriculados en la Diplomatura de Turismo se multiplicó por 2,5 en un contexto en el que la matrícula en estudios de primer y segundo ciclo se redujo en aproximadamente un 25\% (INE, 2010, Estadística de la Enseñanza Universitaria en España. Curso 2008-2009). 
gunos estudios recientes (Nieto y Ramos, 2010) han permitido constatar que la mayoría de los ocupados que realizan actividades de formación o educación no formal están sobreeducados, lo que contribuiría a aumentar su remuneración. La relación entre las diversas dimensiones de la satisfacción de los ocupados con su entorno laboral y su nivel de desajuste educativo se explora con más detalle en el epígrafe 4.

\subsection{Sobreeducación y rendimiento educativo}

\subsubsection{Metodología}

Con el fin de analizar la posible influencia del desajuste educativo sobre el rendimiento económico de la educación se ha estimado una ecuación salarial de tipo minceriano (la ecuación 3) en la que se incorpora dicho desajuste mediante la inclusión de dos variables discretas que permiten analizar las diferencias resultantes en función de si el asalariado se define como adecuadamente educado (categoría de referencia), sobreeducado o infraeducado.

$$
\log W_{i}=\beta_{o}+\beta_{1} E_{i}+\beta_{2} \text { Sobre }+\beta_{3} \text { Infra }+\beta_{4} X_{i}+\beta_{5} X^{2}{ }_{i}+u_{i}
$$

\subsubsection{Estimaciones y resultados}

La Tabla 7 recoge los resultados obtenidos al estimar las ecuaciones 1 y 3 . En relación con esta última, y como cabía esperar, el resultado del coeficiente asociado a la sobreeducación tiene signo negativo y resulta significativo en las tres muestras analizadas, siendo este efecto más acusado en el caso de los trabajadores del sector de turismo y en la muestra total que en la hostelería y restauración. Concretamente el valor esperado medio de las diferencias salariales entre un trabajador sobreeducado respecto a la categoría de referencia (adecuadamente educado) $^{13}$ es de una reducción del 15,69\%, 12,67\% y 6,60\%, para la muestra total, el turismo, y la hostelería y restauración, respectivamente.

Los resultados muestran, por tanto, que los trabajadores sobreeducados obtienen una menor remuneración que aquellos que cuentan con un nivel educativo y experiencias similares y ocupan un puesto de trabajo para el que están adecuadamente educados. La inclusión de las variables que recogen el desajuste educativo en la ecuación 3 ha resultado, por otro lado, en una elevación del rendimiento educativo estimado en relación con el resultante de la ecuación 1. Así, frente a unas cifras del 4,8 (muestra total), 2,7 (turismo) y 2,1 (hostelería y restauración), los rendimientos resultantes de la ecuación 3 se sitúan en el 5,1\%, $3,2 \%$ y $2,5 \%$, respectivamente, que serían las cifras observadas en ausencia de tal desajuste.

\footnotetext{
${ }^{13}$ Calculado como $\left(\exp \beta_{2}-1\right) \times 100$.
} 
Tabla 7

Ecuaciones salariales incluyendo variables que recogen el efecto del desajuste educativo

\begin{tabular}{|c|c|c|c|c|c|c|}
\hline Ln ingresos hora & \multicolumn{2}{|c|}{ Total } & \multicolumn{2}{|c|}{ Turismo } & \multicolumn{2}{|c|}{$\begin{array}{l}\text { Hostelería y } \\
\text { Restauración }\end{array}$} \\
\hline Educación & $\begin{array}{l}0.048^{*} \\
(0.000) \\
\end{array}$ & $\begin{array}{l}0,051^{*} \\
(0.000) \\
\end{array}$ & $\begin{array}{l}0.027^{*} \\
(0.024) \\
\end{array}$ & $0.032^{*}$ & $\begin{array}{l}0.021^{*} \\
(0.003) \\
\end{array}$ & $\begin{array}{l}0.025^{\star} \\
(0.003) \\
\end{array}$ \\
\hline Experiencia & $\begin{array}{l}0.016^{*} \\
(0.000)\end{array}$ & $\begin{array}{l}0.015^{*} \\
(0.000)\end{array}$ & $\begin{array}{l}0.012^{*} \\
(0.002)\end{array}$ & $\begin{array}{l}0.011^{*} \\
(0.002)\end{array}$ & $\begin{array}{l}0.007^{*} \\
(0.003)\end{array}$ & $\begin{array}{l}0.006^{*} \\
(0.003)\end{array}$ \\
\hline Experiencia $^{2}$ & $\begin{array}{l}-0.000^{*} \\
(0.000)\end{array}$ & $\begin{array}{l}-0.000^{*} \\
(0.000)\end{array}$ & $\begin{array}{l}-0.000^{*} \\
(0.000)\end{array}$ & $\begin{array}{l}-0.000^{*} \\
(0.000)\end{array}$ & $\begin{array}{l}-0.000 \\
(0.000)\end{array}$ & $\begin{array}{l}-0.000 \\
(0.000)\end{array}$ \\
\hline Sobreducado & - & $\begin{array}{l}-0.170^{*} \\
(0.007)\end{array}$ & - & $\begin{array}{l}-0.135^{*} \\
(0.020)\end{array}$ & & $\begin{array}{c}-0.068^{*} \\
(0.0269)\end{array}$ \\
\hline Infraeducado & - & $\begin{array}{c}0.024 \\
(0.018)\end{array}$ & - & $\begin{array}{c}0.099 \\
(0.067)\end{array}$ & & $\begin{array}{c}0.162 \\
(0.100)\end{array}$ \\
\hline Constante & $\begin{array}{l}1.248^{*} \\
(0.010)\end{array}$ & $\begin{array}{l}1.258^{*} \\
(0.010)\end{array}$ & $\begin{array}{l}1.474^{*} \\
(0.034)\end{array}$ & $\begin{array}{l}1.472^{*} \\
(0.033)\end{array}$ & $\begin{array}{l}1.496^{*} \\
(0.041)\end{array}$ & $\begin{array}{l}1.487^{\star} \\
(0.041)\end{array}$ \\
\hline $\mathrm{R}^{2}$ & 0.23 & 0.26 & 0.07 & 0.09 & 0.04 & 0.06 \\
\hline $\mathrm{n}$ & 20829 & & 2388 & & 1173 & \\
\hline
\end{tabular}

*Significativo al 1\%; Errores estándard robustos entre paréntesis.

Categoría de referencia: Adecuadamente educado.

Fuente: Elaboración propia a partir de los datos de la ECVT (2006-2009).

Estos resultados contradicen, al menos parcialmente, los postulados de la teoría del capital humano, que vinculan la productividad y los salarios con el nivel de educación, puesto que ésta implica que el rendimiento de la educación debería ser independiente de si el trabajador está o no sobreeducado, y podrían ser más compatibles con la teorías basadas en la competencia por los puestos de trabajo (Thurow, 1975), que en síntesis señalan que el trabajador es retribuido fundamentalmente en función del puesto que desempeña ${ }^{14}$.

\section{SATISFACCIÓN LABORAL EN EL TURISMO: UNA APROXIMACIÓN}

La satisfacción laboral es sin duda una variable que nos aproxima al concepto de calidad de los empleos (Somarriba et al, 2010), siendo éste un indicador del bienestar subjetivo que los trabajadores experimentan en su desempeño laboral (Gamero, 2005 y 2007) ${ }^{15}$. Se trata, además, de un factor determinante en la competitividad de las empresas turísticas (Deery, 2002; Baum, 2007).

${ }^{14}$ Como señalan Aguilar y García (2008) si, de acuerdo con la teoría de la competencia por los puestos de trabajo, los salarios dependen del nivel educativo requerido por los empleos los años de sobreeducación serían improductivos.

${ }^{15}$ En Sánchez et al. (2007) se revisa gran parte de la literatura más reciente sobre este ámbito. 


\subsection{Satisfacción laboral y entorno de trabajo}

En la Tabla 8 se recoge una primera aproximación a los diversos aspectos relacionados con la satisfacción en el trabajo de los ocupados en el sector turístico y en el subsector de hostelería y restauración, en relación con los trabajadores de la economía en su conjunto. Se incluye, para ello, información sobre algunas de las dimensiones sobre las que los encuestados se manifiestan en la ECVT, en una escala de 0 a 10, en la que el menor valor indica un nivel más bajo de satisfacción.

Los resultados ponen de manifiesto unos niveles de satisfacción laboral que en media son ligeramente inferiores en las actividades turísticas en prácticamente todos los aspectos analizados. Es el caso, en particular, del grado de satisfacción laboral en relación con los salarios, la jornada, la flexibilidad de horarios, el tiempo de descanso, vacaciones y permisos, la estabilidad, la formación, y las posibilidades de promoción, entre otros, que reciben valoraciones inferiores en turismo y hostelería siendo, en general, este efecto más acusado en este último grupo. Cabe destacar que las diferencias observadas no son, sin embargo, demasiado significativas dados los estereotipos vigentes sobre el empleo en el sector.

Tabla 8

Grado de satisfacción laboral, comparación turismo, hostelería y muestra total (Media y desviación típica)

\begin{tabular}{|l|c|c|c|}
\hline Satisfacción en el trabajo (escala de $\mathbf{0}$ a 10) & Total & Turismo & $\begin{array}{c}\text { Hostelería y } \\
\text { restauración }\end{array}$ \\
\hline Grado de satisfacción en trabajo actual & 7.19 & 7.07 & 6.96 \\
& $(1.79)$ & $(1.86)$ & $(1.93)$ \\
\hline \multirow{2}{*}{ Grado de satisfacción con su salario } & 6.04 & 5.91 & 5.78 \\
& $(2.23)$ & $(2.28)$ & $(2.36)$ \\
\hline \multirow{2}{*}{ Grado de satisfacción con la jornada } & 7.06 & 6.76 & 6.82 \\
& $(2.22)$ & $(2.36)$ & $(2.36)$ \\
\hline Grado de satisfacción con la flexibilidad de & 6.23 & 6.03 & 6.02 \\
horarios & $(3.02)$ & $(3.06)$ & $(3.08)$ \\
\hline \multirow{2}{*}{ Grado de satisfacción con el tiempo de descanso } & 6.49 & 6.21 & 6.01 \\
& $(2.67)$ & $(2.83)$ & $(2.93)$ \\
\hline \multirow{2}{*}{ Grado de satisfacción con vacaciones y permisos } & 7.35 & 7.10 & 6.91 \\
& $(2.33)$ & $(2.47)$ & $(2.60)$ \\
\hline \multirow{2}{*}{ Grado de satisfacción con la estabilidad } & 7.38 & 7.11 & 6.94 \\
& $(2.52)$ & $(2.55)$ & $(2.63)$ \\
\hline \multirow{2}{*}{ Grado de satisfacción con el ambiente de trabajo } & 7.69 & 7.50 & 7.44 \\
& $(2.64)$ & $(2.25)$ & $(2.27)$ \\
\hline \multirow{2}{*}{ Grado de satisfacción con la actividad desarrollada } & 7.58 & 7.48 & 7.41 \\
& $(1.81)$ & $(1.91)$ & $(1.98)$ \\
\hline \multirow{2}{*}{ Grado de satisfacción con el entorno físico } & 7.07 & 7.05 & 7.19 \\
& $(2.08)$ & $(2.14)$ & $(2.70)$ \\
\hline
\end{tabular}


Tabla 8 (continuación)

Grado de satisfacción laboral, comparación turismo, hostelería y muestra total

(Media y desviación típica)

\begin{tabular}{|l|c|c|c|}
\hline Satisfacción en el trabajo (escala de $\mathbf{0}$ a 10) & Total & Turismo & $\begin{array}{c}\text { Hostelería y } \\
\text { restauración }\end{array}$ \\
\hline Grado de satisfacción con la salud y seguridad & 7.8 & 7.11 & 7.22 \\
& $(2.19)$ & $(2.25)$ & $(2.24)$ \\
\hline Grado de satisfacción con la formación & 5.75 & 5.3 & 5.01 \\
& $(3.07)$ & $(3.24)$ & $(3.36)$ \\
\hline Grado de satisfacción con las ayudas sociales & 3.66 & 3.16 & 2.97 \\
& $(3.03)$ & $(3.27)$ & $(3.25)$ \\
\hline Grado de satisfacción con la organización del & 6.66 & 6.69 & 6.80 \\
trabajo & $(2.29)$ & $(2.32)$ & $(2.36)$ \\
\hline Grado de satisfacción con la & 7.08 & 6.92 & 6.71 \\
autonomía/independencia & $(2.28)$ & $(2.43)$ & $(2.59)$ \\
\hline Grado de satisfacción con el nivel de participación & 6.36 & 6.15 & 6.15 \\
en decisiones & $(2.74)$ & $(2.82)$ & $(2.96)$ \\
\hline Grado de satisfacción con la posibilidad de & 5.00 & 4.83 & 4.80 \\
promociones & $(3.1)$ & $(3.20)$ & $(4.80)$ \\
\hline Grado de satisfacción con la valoración de sus & 6.89 & 6.86 & 6.95 \\
superiores & $(2.34)$ & $(2.42)$ & $(2.44)$ \\
\hline Grado de satisfacción con su desarrollo personal & 7.25 & 7.15 & 7.09 \\
\hline
\end{tabular}

Fuente: Elaboración propia a partir de los datos de la ECVT (2006-2009).

\subsection{Satisfacción laboral y sobreeducación}

Este último apartado se dedica a explorar las relaciones entre satisfacción laboral y sobreeducación para los ocupados del sector turístico. En primer lugar, la Tabla 9 muestra, en este sentido, que los niveles de satisfacción son notoriamente inferiores entre los individuos que consideran que su nivel educativo es mayor que el requerido por el puesto de trabajo que ocupan. Se trata de una relación que se observa en todas las dimensiones de la satisfacción laboral analizadas.

En segundo lugar, y siguiendo a Gamero (2005), se considera que la satisfacción laboral que el individuo declara (que puede tomar valores de 0 a 10 niveles de satisfacción, Satis $_{i}$ ) es un indicador ordinal de la variable latente de bienestar subjetivo en el trabajo $\left(\mathrm{BST}_{\mathrm{i}}\right)$. Esta variable se divide en intervalos, asociados a los distintos niveles de satisfacción que puede seleccionar el trabajador. A partir de un modelo probit ordenado, adecuado cuando la variable a estimar tiene una escala numérica y ordinal, se realiza, para finalizar, un análisis de la relación entre la satisfacción de los trabajadores de turismo y variables como la educación, el desajuste educativo y otras relativas a su nivel salarial, horas de trabajo, tener un contrato de carácter eventual y la experiencia. 
Tabla 9

Satisfacción laboral de los trabajadores del sector turístico en función de la adecuación de su formación con los requerimientos del puesto que ocupan

\begin{tabular}{|c|c|c|}
\hline Satisfacción en el trabajo (escala de 0 a 10) & Adecuados & Sobreeducados \\
\hline Grado de satisfacción en trabajo actual & $\begin{array}{c}7.32 \\
(1.72)\end{array}$ & $\begin{array}{c}6.21 \\
(2.00)\end{array}$ \\
\hline Grado de satisfacción con su salario & $\begin{array}{c}6.18 \\
(2.16) \\
\end{array}$ & $\begin{array}{c}5.09 \\
(2.44) \\
\end{array}$ \\
\hline Grado de satisfacción con la jornada & $\begin{array}{r}6.92 \\
(2.30) \\
\end{array}$ & $\begin{array}{c}6.33 \\
(2.47) \\
\end{array}$ \\
\hline Grado de satisfacción con la flexibilidad de horarios & $\begin{array}{c}6.25 \\
(2.96)\end{array}$ & $\begin{array}{c}5.30 \\
(3.22) \\
\end{array}$ \\
\hline Grado de satisfacción con el tiempo de descanso & $\begin{array}{c}6.45 \\
(2.73) \\
\end{array}$ & $\begin{array}{c}5.45 \\
(2.99) \\
\end{array}$ \\
\hline Grado de satisfacción con vacaciones y permisos & $\begin{array}{c}7.31 \\
(2.34)\end{array}$ & $\begin{array}{c}6.36 \\
(2.74)\end{array}$ \\
\hline Grado de satisfacción con la estabilidad & $\begin{array}{c}7.32 \\
(2.40)\end{array}$ & $\begin{array}{c}6.40 \\
(2.89)\end{array}$ \\
\hline Grado de satisfacción con el ambiente de trabajo & $\begin{array}{c}7.62 \\
(2.16)\end{array}$ & $\begin{array}{c}7.04 \\
(2.54) \\
\end{array}$ \\
\hline Grado de satisfacción con la actividad desarrollada & $\begin{array}{c}7.74 \\
(1.73)\end{array}$ & $\begin{array}{c}6.60 \\
(2.17)\end{array}$ \\
\hline Grado de satisfacción con el entorno físico & $\begin{array}{c}7.27 \\
(2.08) \\
\end{array}$ & $\begin{array}{c}6.34 \\
(2.21) \\
\end{array}$ \\
\hline Grado de satisfacción con la salud y seguridad & $\begin{array}{c}7.28 \\
(2.18) \\
\end{array}$ & $\begin{array}{c}6.58 \\
(2.38) \\
\end{array}$ \\
\hline Grado de satisfacción con la formación & $\begin{array}{c}5.70 \\
(3.16) \\
\end{array}$ & $\begin{array}{c}4.04 \\
(3.14) \\
\end{array}$ \\
\hline Grado de satisfacción con las ayudas sociales & $\begin{array}{c}3.44 \\
(3.34) \\
\end{array}$ & $\begin{array}{c}2.32 \\
(2.90) \\
\end{array}$ \\
\hline Grado de satisfacción con la organización del trabajo & $\begin{array}{c}6.96 \\
(2.19) \\
\end{array}$ & $\begin{array}{c}5.90 \\
(2.48) \\
\end{array}$ \\
\hline Grado de satisfacción con la autonomía/independencia & $\begin{array}{c}7.15 \\
(2.29)\end{array}$ & $\begin{array}{c}6.14 \\
(2.69) \\
\end{array}$ \\
\hline $\begin{array}{l}\text { Grado de satisfacción con el nivel de participación en } \\
\text { decisiones }\end{array}$ & $\begin{array}{c}6.41 \\
(2.76)\end{array}$ & $\begin{array}{c}5.24 \\
(3.07)\end{array}$ \\
\hline Grado de satisfacción con la posibilidad de promociones & $\begin{array}{c}5.08 \\
(3.22) \\
\end{array}$ & $\begin{array}{c}3.88 \\
(3.05) \\
\end{array}$ \\
\hline Grado de satisfacción con la valoración de sus superiores & $\begin{array}{c}7.07 \\
(2.33)\end{array}$ & $\begin{array}{c}6.16 \\
(2.53)\end{array}$ \\
\hline Grado de satisfacción con su desarrollo personal & $\begin{array}{c}7.48 \\
(1.93)\end{array}$ & $\begin{array}{c}6.04 \\
(2.51)\end{array}$ \\
\hline
\end{tabular}

Fuente: Elaboración propia a partir de los datos de la ECVT (2006-2009). Para cada ítem se indica la media y, entre paréntesis, la desviación típica. 
Tabla 10

Estimación probit ordenado de la satisfacción

\begin{tabular}{|c|c|c|}
\hline Satisfacción & Modelo 1 & Modelo 2 \\
\hline Educación & $\begin{array}{l}0.021^{*} \\
(0.006)\end{array}$ & - \\
\hline$E_{2}$ & - & $\begin{array}{l}-0.038 \\
(0.060)\end{array}$ \\
\hline$E_{3}$ & - & $\begin{array}{c}0.038 \\
(0.069)\end{array}$ \\
\hline $\mathrm{E}_{4}$ & - & $\begin{array}{c}0.119^{* \star \star} \\
(0.071)\end{array}$ \\
\hline$E_{5}$ & - & $\begin{array}{l}0.213^{* *} \\
(0.080)\end{array}$ \\
\hline Sobreeducado & $\begin{array}{l}-0.666^{*} \\
(0.056)\end{array}$ & $\begin{array}{l}-0.672^{*} \\
(0.057)\end{array}$ \\
\hline Temporal & $\begin{array}{l}-0.179^{*} \\
(0.050)\end{array}$ & $\begin{array}{l}-0.178^{*} \\
(0.050)\end{array}$ \\
\hline Salario (Log) & $\begin{array}{l}0.263^{*} \\
(0.065)\end{array}$ & $\begin{array}{l}0.264^{*} \\
(0.065)\end{array}$ \\
\hline $\begin{array}{l}\text { Horas de trabajo } \\
\text { (Log) }\end{array}$ & $\begin{array}{l}-0.395^{*} \\
(0.066)\end{array}$ & $\begin{array}{l}-0.393^{*} \\
(0.066)\end{array}$ \\
\hline Experiencia & $\begin{array}{c}-0.010^{\star \star *} \\
(0.006) \\
\end{array}$ & $\begin{array}{l}-0.009 \\
(0.006) \\
\end{array}$ \\
\hline Experiencia $^{2}$ & $\begin{array}{l}0.000^{* *} \\
(0.000)\end{array}$ & $\begin{array}{c}0.000^{* * *} \\
(0.000) \\
\end{array}$ \\
\hline $\begin{array}{l}\text { N } \\
\text { Log likelihood } \\
\text { Test de razón de } \\
\text { verosimilitudes } \\
\text { PseudoR }^{2}\end{array}$ & $\begin{array}{c}2388 \\
-4479.96 \\
221.50 \\
0.024\end{array}$ & $\begin{array}{c}2388 \\
-4478.22 \\
224.99 \\
0.024\end{array}$ \\
\hline
\end{tabular}

${ }^{*}$ significativo al $1 \%$; ${ }^{* *}$ significativo al $5 \% .{ }^{* * *}$ significativo al $10 \%$.

Errores estándar entre paréntesis.

Fuente: Elaboración propia a partir de los datos de la ECVT (20062009).

Como puede observarse en la Tabla 10, en el modelo 1, en el que la educación se considera en forma de variable continua, los años de educación tienen un efecto positivo y significativo en la satisfacción laboral del trabajador; sin embargo, en el modelo 2, cuando se introduce la variable educación por niveles de estudios, resultan significativos únicamente los niveles de estudios más altos, especialmente el universitario. Salario (signo positivo) y horas de trabajo semanales (signo negativo) afectan la satisfacción en el sentido que cabría esperar, 
asimismo también se observa la reducción que experimentan los trabajadores en su satisfacción por el hecho de estar contratados eventualmente. En cuanto a la variable de interés en este epígrafe, se observa un efecto significativo y negativo de la sobreeducación ${ }^{16}$ sobre la satisfacción, que confirma las conclusiones de los análisis descriptivos previos. Estos resultados son coherentes con otros como, por ejemplo, los de Lam et al. (2000), quienes concluyen que el nivel de satisfacción entre los empleados hoteleros de su muestra es notoriamente menor entre los más cualificados, aunque en su estudio no analizan el grado de sobreeducación de tales trabajadores.

Para concluir cabe señalar que los resultados de este análisis, unidos a los del epígrafe 2, conducen a la inequívoca conclusión de que es necesario mejorar la asignación de puestos de trabajo en relación con los niveles educativos de los ocupados. Por un lado, los sobreeducados tienen unos rendimientos de la educación que son sustancialmente inferiores a los de los trabajadores de su misma formación y que se consideran correctamente asignados a sus puestos de trabajo en estos términos. Por otro, los aspectos no pecuniarios del entorno laboral de los sobreeducados no parecen compensar esa diferencia salarial sino que, al contrario, la acentúan, dado que sus niveles de satisfacción con las dimensiones analizadas son claramente inferiores a los de los trabajadores que consideran que su formación es adecuada para el puesto que ocupan. Aunque parece razonable que exista un cierto nivel de desajuste educativo (sobreeducación) en puestos de entrada, especialmente en las primeras etapas de la vida laboral, no parece que la permanencia de los trabajadores en puestos inferiores a su nivel educativo y con menor retribución sea una buena estrategia para las empresas del sector pues este aspecto lastra la motivación de este grupo de empleados. Su satisfacción con el trabajo realizado es menor que la del resto de trabajadores y ello puede llegar a afectar negativamente a su productividad y a la atención al cliente en uno de los sectores en el que el capital humano tiene una mayor relevancia relativa.

\section{CONCLUSIONES}

El turístico es uno de los sectores de actividad con una mayor capacidad de generación de empleo en España. Se trata, además, de un sector que ha resistido especialmente bien en los peores momentos del reciente ciclo económico y en el que se ocupan en mayor proporción algunos de los colectivos de trabajadores entre los cuales las variables laborales alcanzan sus peores valores. Sin embargo, es indudable que, al igual que ocurre con el conjunto de la economía, deben introducirse cambios en el modelo de negocio que permitan generar un mayor valor añadido y alcanzar mayores cotas de productividad. Ello pasa por un

\footnotetext{
${ }^{16}$ Se ha comprobado que estar adecuadamente educado no es significativo.
} 
incremento neto de capital humano en el sector, que destaca por la baja cualificación promedio de sus ocupados, tal y como se ha mostrado en el artículo. Mayores dotaciones de capital humano contribuyen, como es sabido, a mejorar la capacidad de adaptación y flexibilidad en las distintas tareas necesarias para la mejora de los procesos, la gestión y la calidad de servicio en todos los niveles jerárquicos.

Los resultados alcanzados en el artículo, obtenidos a partir de datos muy recientes, ponen de manifiesto una aparente paradoja: la sobreeducación (esto es, la existencia de trabajadores cuyo nivel formativo es mayor que el que se requiere para desempeñar las tareas inherentes al puesto de trabajo que ocupan) es mayor en este sector que en la economía en su conjunto cuando, por otro lado, el peso relativo de los trabajadores con mayores niveles educativos es mucho menor que en aquélla. El problema tiene, lógicamente, una doble dimensión: por un lado, las características de la propia actividad, muy intensiva en el uso de la mano de obra, pueden hacer que los empleos con mayores requerimientos en cuanto a conocimientos, competencias o habilidades sean menos abundantes que en otros sectores de actividad; por otro lado, puede que se haya producido un aumento excesivo de la oferta de trabajadores más cualificados en detrimento de otros grupos cuya formación sea más acorde a las necesidades del sector. Los análisis realizados han puesto de manifiesto, en cualquier caso, que los rendimientos salariales que los trabajadores obtienen a cambio de su inversión en educación son menores en las actividades turísticas que en el resto de la economía, y que los niveles generales de satisfacción de los ocupados con las diversas dimensiones de su entorno laboral analizadas son también inferiores, aunque en este caso quizá no tanto como cabría esperar dada la imagen más estereotipada del sector. Los resultados muestran, además, que los sobreeducados tienen una penalización salarial en relación con quienes, con su misma formación, ocupan puestos más acordes con ésta. A este factor pecuniario se une, además, unos niveles de satisfacción laboral claramente inferiores a los de quienes no experimentan desajuste educativo. En un sector donde el capital humano es fundamental este descontento puede resultar especialmente negativo no sólo en términos de bienestar individual de los ocupados sino también en cuanto a los niveles de productividad y aspectos relacionados con la calidad del servicio prestado.

Parece claro, por tanto, que no basta con señalar que debe aumentarse el nivel formativo de los activos en el sector turístico como un mecanismo para elevar la competitividad del sector. Si las mayores dotaciones de capital humano no van acompañadas de un cambio cualitativo en los empleos disponibles en el sector esta estrategia podría resultar contraproducente. Es, en este sentido, necesario acompasar, desde el punto de vista de la oferta de trabajo, los niveles de formación que reciben los estudiantes con las necesidades reales del sector para evitar que la sobreeducación se consolide como una característica estructural del 
sector, a la vez que se actúa sobre los cambios en las formas de producción y en las actividades ofrecidas de tal forma que se eleve el nivel general de calidad del empleo en el sector.

Por ello es tan relevante el desarrollo de una política educativa especializada en turismo, en todos los ámbitos, ocupacional, secundaria (formación profesional) y universitaria (grado; master y/o doctorado). Resulta imprescindible generar sinergias con el tejido productivo (logrando una educación turística capaz de recoger las necesidades de formación demandadas por el entorno empresarial), diseñando competencias generales y específicas que tengan en cuenta tanto los perfiles profesionales como las capacidades que deben ser desarrolladas en cada uno de los ámbitos de la educación relacionada con el turismo. Asimismo, resulta necesario promover entre los empresarios turísticos la demanda de capital humano formado en las distintas titulaciones oficiales de especialización turística al que consideren bien preparado, al que valoren y recompensen adecuadamente, no solo en términos retributivos sino también con el logro de objetivos de satisfacción laboral en el empleo, lo que lógicamente podrá redundar en la generación de empleos de calidad en la industria turística que se contrapongan a elementos preconcebidos de precariedad generalizada en el sector y lo hagan más atractivo para el capital humano.

\section{REFERENCIAS BIBLIOGRÁFICAS}

ACOSTA, A.J.; FERNÁNDEZ, N. y MOLLÓN, M. (2002). Recursos humanos en empresas de turismo y hostelería, Madrid: Prentice Hall.

AGUILAR, M.I.y GARCÍA-CRESPO, D. (2008). "Desajuste educativo y salarios en España”, Estadística Española, 50(168), 393-426.

ALBA-RAMÍREZ, A. y SAN SEGUNDO, M. J (1995). "The returns to education in Spain", Economics of Education Review, 14(2), 155-166.

ARRAZOLA, M. y HEVIA, J. (2008). "Three measures of returns to education: An illustration for the case of Spain", Economics of Education Review, 27, 266-275.

BECKER, G.S. (1964). Human Capital: A Theoretical and Empirical Analysis, With Special Reference to Education, New York, National Bureau of Economic Research.

BAUM, T. (2007): "Human resources in tourism: Still waiting for a change", Tourism Management, 28, 1383-1399.

BLANCO, J.M. (1997): "Comentarios acerca del desajuste educativo en España”, Papeles de Economía Española, 72, 275-291. 
CAMPOS-SORIA, J. A.; ORTEGA-AGUAZA,B Y ROPERO-GARCÍA, MA.(2009): "Gender segregation and wage diferences in hospitality indus-try", Tourism Economics, 15(4), 847-866.

CAMPOS-SORIA, J. A.; MARCHANTE-MERA, A. y ROPERO-GARCÍA, MA. (2011): "Patterns of ocupational segregation by gender in the hospitality industry"; Internacional Journal of Hospitality Management, 30, pp.91-102.

DEERY, M. (2002): "Labour Turnover in International Hospitality and Tourism". En D'Annunzio-Green, N.; Maxwell, G. y Watson, S. (ed): Human resource management: international perspectives in hospitality and tourism (pp.5163). Londres: Thomson.

EXCELTUR (2004). Libro Blanco de los Recursos Humanos en turismo.

GAMERO, C. (2005). Análisis macroeconómico de la satisfacción laboral. CES, Consejo Económico y Social.

GAMERO, C. (2007). "Satisfacción laboral y tipo de contrato en España", Investigaciones Económicas, 31(3), 415-444.

GAMERO, C. (2010) "Satisfacción laboral de los asalariados inmigrantes", Revista de Economía Aplicada, 54, 33-56.

INSTITUTO DE ESTUDIOS TURÍSTICOS (2009a). Balance del turismo. Año 2009.

INSTITUTO DE ESTUDIOS TURÍSTICOS (2009b). Empleo en el sector de turístico. Informe anual 2009.

LAM, T.; ZHANG, H. y BAUM, T. (2000), "An investigation of employees' job satisfaction: the case of hotels in Hong Kong", Tourism Management, 22, 157-165.

LILLO, A. (2009a). El capital humano como estrategia competitiva en el sector turístico español, "IV Premio Internacional de Estudios Turísticos Gabriel Escarrer". Universidad de Islas Baleares, Edicions UIB.

LILLO, A. (2009b). "El papel del capital humano en el sector turístico: algunas reflexiones y propuestas", Cuadernos de Turismo, 24, 53-64.

LILLO, A. Y CASADO, JM. (2010a). "Rewards to education in the tourism sector: one step ahead", Tourism Economics, 16(1), 11-23.

LILLO, A. Y CASADO, JM. (2010b)."On the rewards to education in Spain: Endogeneity and regional differences", Regional and Sectoral Economic Studies, 10(3), 37-54.

LILLO-BAÑULS, A. Y RAMÓN-RODRIGUEZ, A.B. (2005). "Returns to education in the Spanish tourism labour market", Tourism Economics, 11(1), 119132.

MARCENARO, O.D. y NAVARRO, M.L. (2005). "Nueva evidencia sobre el rendimiento del capital humano en España". Revista de Economía Aplicada, 37 (2), 69-88. 
MARCHANTE, A.; ORTEGA, B. y PAGÁN, R. (2003). "Desajuste educativo y salariales: Nueva evidencia para el caso español", Revista Asturiana de Economía, 28, 131-158.

MARCHANTE, A.; ORTEGA, B. y PAGÁN, R. (2005), "Educational mismatch and wages in the hospitality sector", Tourism Economics, 11(1), 103-117.

MINCER, J. (1974) Schooling, Experience and Earnings. NBER, New York (reprinted in 1993 by Gregg Revivals, Aldershot, UK, and Brookfield, USA).

MURILLO, I.P.; RAHONA, M. y SALINAS, M.M. (2010). Efectos del desajuste educativo sobre el rendimiento privado de la educación: un análisis para el caso español (1995-2006), Fundación de las Cajas de Ahorros, Documento de Trabajo $\mathrm{N}^{\circ}$ 520/2010.

NIETO, S. y RAMOS, R. (2010). Sobreeducación, educación no formal y salarios: evidencia para España. Fundación de las Cajas de Ahorros, Documento de trabajo $N^{\circ} 577 / 2010$.

OCDE (2010) OECD Tourism Trends and Policies 2010.

OLIVER, J.; RAYMOND, J.L.; ROIG, J.L. y BARCEINAS, F. (1999). "Return to human capital in Spain: A survey of the evidence" in R. Asplun \& P. Telhado (Eds.) Returns to Human Capital in Europe, Helsinki, The Research Institute of the Finnish Economy.

PASTOR, JM; RAYMOND, J.L.; ROIG, J.L. y SERRANO, L. (2007). El rendimiento del capital humano en España. IVIE. Fundación Bancaja.

RAYMOND, J.L.; ROIG, J.L. y GÓMEZ, L.M. (2009). "Rendimientos de la educación en España y movilidad intergeneracional". Papeles de Economía Española, 119, 188-205.

SÁNCHEZ, S.M.; ARTACHO, C.; FUENTES, F.J. y LÓPEZ-GUZMÁN, T.J. (2007): "Análisis de los determinantes estructurales de la satisfacción laboral. Aplicación en el sector educativo", Estudios de Economía Aplicada, vol. 25-3, 867-900.

SANTOS, L.D., y VAREJÃO, J. (2007). 'Employment, pay and discrimination in the tourism industry', Tourism Economics, Vol 13, No 2, 225-240.

SOMARRIBA, N.; MERINO, M.C.; RAMOS, G. y NEGRO, A. (2010) "La calidad del trabajo en la Unión Europea”, Estudios de Economía Aplicada, vol. 28-3, 1-22.

THRANE, C. (2008). "Earnings differentiation in the tourism industry: Gender, human capital and socio-demographic effects", Tourism Management, No 29, 514-524.

THRANE, C. (2010). "Education and earnings in the tourism industry: the role of sheepskin effects", Tourism Economics, 16(3), 549-563.

THUROW, L. C. (1978). Inversión en capital humano, Editorial Trillas, México.

THUROW, L. C. (1983). "Un modelo de competencia por los puestos de trabajo", in M. Piore (ed.), Paro e inflación, Alianza Universidad, Madrid, 57-76. 


\section{ANEXOS}

Tabla 11

Estadísticos descriptivos

\begin{tabular}{|c|c|c|}
\hline \multirow[b]{2}{*}{ Variables } & \multicolumn{2}{|c|}{ Muestra Total } \\
\hline & Media & Desv. Std. \\
\hline Educación (años) & 10,66 & 4.10 \\
\hline Ingresos hora & 7.70 & 4.58 \\
\hline Logaritmo ingresos hora & 1.93 & 0.42 \\
\hline Experiencia & 19.30 & 11.97 \\
\hline Contratado fijo* & 0.77 & \\
\hline \multirow[t]{2}{*}{ Contratado temporal $^{*}$} & 0.23 & \\
\hline & \multicolumn{2}{|c|}{ Turismo } \\
\hline Variables & Media & Desv. Std. \\
\hline Educación (años) & 9.54 & 3.64 \\
\hline Ingresos hora & 6.95 & 4.07 \\
\hline Logaritmo ingresos hora & 1.84 & 0.40 \\
\hline Experiencia & 18.31 & 12.03 \\
\hline Contratado fijo* & 0.72 & \\
\hline \multirow[t]{2}{*}{ Contratado temporal $^{*}$} & 0.28 & \\
\hline & \multicolumn{2}{|c|}{ Hostelería y restauración } \\
\hline Variables & Media & Desv. Std. \\
\hline Educación (años) & 9.06 & 3.49 \\
\hline Ingresos hora & 6.18 & 2.91 \\
\hline Logaritmo ingresos hora & 1.74 & 0.36 \\
\hline Experiencia & 16.85 & 12.09 \\
\hline Contratado fijo* & 0.67 & \\
\hline Contratado temporal $^{*}$ & 0.33 & \\
\hline
\end{tabular}

* Representa el porcentaje en la muestra.

Fuente: Elaboración propia a partir de los datos individuales de la Encuesta de Calidad de Vida en el Trabajo 2006-2009. 
Tabla 12

Ecuaciones salariales en turismo por género

(número de años de educación)

\begin{tabular}{|l|c|c|c|c|c|c|c|c|}
\hline & \multicolumn{4}{|c|}{ Turismo } & \multicolumn{3}{c|}{ Hostelería y restauración } \\
\hline & \multicolumn{2}{|c|}{ Mujeres } & \multicolumn{2}{c|}{ Hombres } & \multicolumn{2}{c|}{ Mujeres } & \multicolumn{2}{c|}{ Hombres } \\
\hline Ln ingresos hora & Coef. & $\mathbf{t}$ & Coef. & $\mathbf{t}$ & Coef. & $\mathbf{t}$ & Coef. & $\mathbf{t}$ \\
\hline Educación & $\begin{array}{c}0.027^{*} \\
(0.003)\end{array}$ & 7.60 & $\begin{array}{c}0.028^{*} \\
(0.003)\end{array}$ & 8.44 & $\begin{array}{c}0.019^{*} \\
(0.004)\end{array}$ & 4.91 & $\begin{array}{c}0.023^{*} \\
(0.005)\end{array}$ & 4.41 \\
\hline Experiencia & $\begin{array}{l}0.010^{*} \\
(0.003)\end{array}$ & 3.09 & $\begin{array}{c}0.013^{*} \\
(0.003)\end{array}$ & 4.50 & $\begin{array}{c}0.011^{*} \\
(0.003)\end{array}$ & 3.01 & $\begin{array}{c}0.004 \\
(0.004)\end{array}$ & 1.07 \\
\hline Experiencia $^{2}$ & $\begin{array}{c}-0.000 \\
(0.000)\end{array}$ & -1.91 & $\begin{array}{c}-0.000^{* *} \\
(0.000)\end{array}$ & -2.80 & $\begin{array}{c}-0.000^{* *} \\
(0.000)\end{array}$ & -2.05 & $\begin{array}{c}-0.000 \\
(0.000)\end{array}$ & 0.29 \\
\hline Constante $^{1.440^{*}}$ & 27.85 & $\begin{array}{c}1.503^{*} \\
(0.045)\end{array}$ & 33.04 & $\begin{array}{c}1.457^{*} \\
(0.051)\end{array}$ & 28.24 & $\begin{array}{c}1.551^{*} \\
(0.065)\end{array}$ & 23.66 \\
\hline $\mathrm{R}^{2}$ & $0.051)$ & & 0.078 & & 0.05 & & 0.05 & \\
\hline $\mathrm{n}$ & 971 & & 1417 & & 661 & & 512 & \\
\hline
\end{tabular}

*Significativo al $1 \%$.

** Significativo al $5 \%$.

Errores estándard robustos entre paréntesis.

Fuente: Elaboración propia a partir de los datos individuales de la Encuesta de Calidad de Vida en el Trabajo 2006-2009 (Ministerio de Trabajo e Inmigración). 